\title{
Relationships between individual behaviour and morphometry under different experimental conditions of temperature and feeding in glass eels (Anguilla anguilla)
}

\author{
A. Bardonnet ${ }^{(1,2)}$, J. Labonne ${ }^{(1,2)}$, J. Laffite ${ }^{(1,2)}$, J. Garnier ${ }^{(1,2)}$ \\ Received October 2nd, 2008 / Reçu le 2 octobre 2008 \\ Revised January 9, 2009 / Révisé le 9 janvier 2009 \\ Accepted January 13, 2009 / Accepté le 13 janvier 2009
}

Key-words: body condition, behaviour, pigmentation, migration, colonization, glass eel

\section{ABSTRACT}

\begin{abstract}
After Anguilla anguilla larvae reach the European coast, metamorphosing glass eels exhibit an estuarine migration phase and can potentially colonize the continental area. Associated behaviours to upstream movement in estuary and river basin differ strongly: passive tidal transport in estuary, active swimming beyond the upstream tidal limit. Moreover, the migratory behaviour may shift towards a density-dependent dispersal beyond this limit. A positive relationship has previously been established between glass eels' body condition and migratory behaviour in estuary and also higher in the river basin. An experiment was settled to test for the density-dependent versus migratory behaviour under controlled conditions. The relationships between some behaviours (swimming, grouping, feeding, and aggressiveness) and body condition was investigated at the individual level. Two controlled factors were crossed, leading to four combinations of high and low levels of food and temperature. The high level of food led to a lesser loss in body condition. Swimming activity was positively related to initial body condition and loss in body condition, but these two variables were not related to aggressiveness. We conclude that the density-dependent dispersal hypothesis was not reinforced by these present results.
\end{abstract}

\section{RÉSUMÉ}

Relations entre comportement individuel et morphométrie sous différentes conditions expérimentales de température et de nourriture chez les anguilles européennes (Anguilla anguilla)

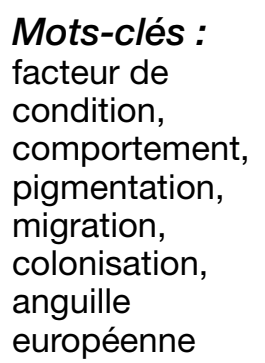

L'anguille européenne est un poisson migrateur dont les larves parviennent jusqu'à nos côtes où elles se métamorphosent en civelles qui colonisent le milieu continental après une phase de migration estuarienne, suivie ou non par la colonisation du bassin versant. Les comportements associés au déplacement amont dans ces deux milieux diffèrent fortement : une nage " portée " par le courant durant le flot en estuaire, une nage active en limite amont d'estuaire. Une corrélation positive a déjà été établie entre le facteur de condition et le potentiel migratoire de l'anguille (que ce soit en estuaire ou en phase de colonisation du bassin versant). Par ailleurs,

(1) INRA, UMR Ecobiop, Station d'Hydrobiologie, Quartier Ibarron, 64310 St Pée sur Nivelle, France, bardonne@st-pee.inra.fr

(2) UPPA, UMR Ecobiop, Station d'Hydrobiologie, Quartier Ibarron, 64310 St Pée sur Nivelle, France 
une dispersion densité-dépendante pourrait prendre le relais d'un comportement de migration à partir de cette limite. Une expérimentation a été conduite en milieu contrôlé pour tester cette hypothèse. Un suivi a été réalisé à l'échelle individuelle pour mettre en relation certains comportements (nage, grégarité, recherche de nourriture, agressivité) avec le facteur de condition. Les conditions expérimentales ont été manipulées de manière à croiser deux niveaux de température et deux niveaux d'alimentation. Le niveau d'alimentation haut a limité la perte d'embonpoint, mais l'activité de nage, positivement corrélée à l'embonpoint initial et à la perte d'embonpoint, n'a pu être reliée à l'agressivité. L'hypothèse de la dispersion densité-dépendante n'est donc pas renforcée par les résultats obtenus ici.

\section{INTRODUCTION}

Like others temperate eels, European eel (Anguilla anguilla) has undergone a constant decline during the last 20 years. Lower yellow eels production have been reported in many places widespread in Europe and a general decrease in recruitment is observed (Moriarty and Dekker, 1997). Quite recently, scientists have highlighted different migratory patterns thanks to otoliths micro-chemical studies, leading to the idea that temperate eels were facultative catadromous (Daverat et al., 2006). If the estuarine glass eel migration is largely documented, much less attention has been devoted to the process of river colonization by pigmenting glass eels (also called elvers). Glass eels which enter estuary are still slightly ventro-laterally flattened (in echo of the willow-like shaped leptocephalus larvae) and fully unpigmented. According to most authors, metamorphosis will end with the complete development of melanophores (Elie et al., 1982). Many others changes go with this external change in transparency: structural, with the development of teeth and change in the digestive tract (Elie, 1979); biometric, with a reduction in length and weight (Lecomte-Finiger, 1983) and physiologic with the change in the level of thyroid hormones (Yamano et al., 2007) and osmotic regulation capacity (Sasai et al., 2007). These changes go on in the course of the estuarine migration which is supposed to end close to the upstream tidal limit where migrants would accumulate. Swimbladder remains non-functional during the estuarine migration probably because dynamic lift has a lower energetic cost associated with the selective tidal stream transport (Hickman, 1981). After this first step of continental progress, little is known about the physiologic, morphometric and behavioural changes which will influence the river colonization migratory pattern.

Once the limit of flood influence is reached, fish will have to swim against the current to progress upstream (Deelder, 1958; Jellyman, 1977; Sorensen and Bianchini, 1986). The departure from the upstream tidal limit area towards the river basin does not concern all individuals and may play a role in the occurrence of the two phenotypes, migrants and estuarine residents, even if the reality is much more complex since additional phenotypes alternating estuarine/river residency and following more or less complex patterns during older stages are also observed (Daverat et al., 2004). For these individuals, which have reached the upstream tidal limit, two main theories are proposed to explain the mechanisms at work in the river colonization process. The first one refers to a mass directed movement leading fish to swim against the current and disperse upstream, whilst the second one proposes that nonoriented dispersion will end in an apparent upstream movement under the hypothesis of density-dependent settlement (Ibbotson et al., 2002). This latter theory thus clearly implies a major influence of density on demography, behaviour and phenotypic variability. Some ground facts may support this point of view: for instance, aggressiveness has been observed in glass eels (Wattendorf, 1979; Bardonnet et al., 2005) and eel productivity is negatively related to density (Vollestad and Jonsson, 1988). After a progressive increase in glass eels abundance density from the middle to the upper estuary, abundances decrease sharply (Edeline et al., 2007). At this tidal limit, fish are supposed to have a resting phase (Gascuel et al., 1995), where they may resume feeding to increase energetic stores, before possibly undertaking a further upstream colonization (Moriarty, 1986; Naismith and Knights, 1988; 
Feunteun et al., 2003). Once fish has resumed feeding, energetic status and body condition both partly reflects the local availability of food and the degree of competition to get access to this resource. Recent results have underlined the positive role of elver body condition in locomotor activity (Imbert et al., 2008). Interestingly, glass eels' body condition (Edeline et al., 2006) and energetic status (Bureau du Colombier et al., 2007) are also involved in settlement. At the same stage, competition for shelter may induce upstream movement, and a temporal change in intra-specific relationship from gregarious to territorial has been observed in pigmenting eels (Bardonnet et al., 2005). Then, the relative importance of density-dependent mechanisms in river colonization could change according to ontogeny, fish energetic status, and environmental conditions. Besides the change in hydraulic conditions (tidal limit), temperature may also affect migratory pattern through feeding and growth rate efficiency, and also because temperature could act as a cue in the departure decision from the tidal limit area. Indeed, data analyses on catches at fish-ladders located at the downstream end of the river basin, close to the estuary upstream limit, indicate that water temperature could play a crucial role in determining the departure from the area where elvers accumulated, with a $14{ }^{\circ} \mathrm{C}$ threshold (White and Knights, 1997). Salinity would not be an important factor as glass eels are capable to withstand quick and large change in salinity (Crean et al., 2005) and also because at the tidal limit, salinity is most of the time close to zero.

In the present paper, we provide an experimental test of the relationships between densitydependence, individual behaviour and morphometric condition, in order to investigate the mechanisms possibly underlying lbbotson's second theory. To do so, we sampled fish at the end of the fishing season close to the tidal upstream limit, as potential river colonizers. The experiment was conducted at two close temperature levels to test for the influence of the $14{ }^{\circ} \mathrm{C}$ threshold on fish behaviour, and at two close feeding levels to test for competition and aggressive behaviour. Fish metamorphosis process was followed through body pigmentation and its link with fish behaviour and change in body condition was investigated.

\section{MATERIAL AND METHODS}

\section{$>$ EXPERIMENTAL SETUP}

Glass eels (Anguilla anguilla) were collected in freshwater by professional fishermen (pushing nets) on $1^{\text {st }}$ March 2006 at St Laurent le Pil $\left(-0.2^{\circ} \mathrm{W}, 45^{\circ} \mathrm{N}\right)$ on the Isle River (Dordogne river's tributary, France), close to the upstream limit of tide influence. Fish were kept in aerated water $\left(8^{\circ} \mathrm{C}\right)$ and between 3 and 6 March, they were individually weighed $( \pm 0.1 \mathrm{mg})$, measured $( \pm 0.5 \mathrm{~mm})$, and their pigmentation stages assessed following Elie et al. (1982) criteria. They were distributed in 16 groups of ten fish (density $=80$ glass eels or $24 \mathrm{~g} \cdot \mathrm{m}^{-2}$ ) and each fish among ten was individually marked (one or two tags among four colours of Visible Implant Elastomere, Northwest Marine technology). Sixteen aquaria were settled in a room where air temperature was maintained at $8{ }^{\circ} \mathrm{C}$. Each aquarium $(50 \mathrm{~cm} \times 25 \mathrm{~cm})$ was filled with $13 \mathrm{~cm}$ of tap water re-circulated by a pump. In each aquarium, nine pieces of artificial vegetation (10 cm long) pasted on the aquarium floor in a regularly spaced manner mimicked Elodae shelters. Light came from two different points in the room in order to limit differences among aquaria and provided an $11 \mathrm{~L} / 13 \mathrm{D}$ photoperiod. Daylight varied from 5 to 10 lux at the water surface, depending on the position of the aquaria in the room.

According to literature, the $12{ }^{\circ} \mathrm{C}$ and $14{ }^{\circ} \mathrm{C}$ values correspond respectively to the thresholds in glass eel feeding (Elie, 1979) and glass eel upriver movement (White and Knights, 1997). Because temperature is a meaningful factor acting on development (Briand et al., 2005), we therefore chose to set the experimental temperatures within a short range. The temperature of all aquaria was regulated by thermo-resistances, to reach $11-12{ }^{\circ} \mathrm{C}$ in half of them and $14-15^{\circ} \mathrm{C}$ in the eight remaining. Concerning feeding levels, their choice was constrained by the possibility of direct observation of agonistic acts. Video recording was not used because width and depth of field were not adapted to an accurate reading of marks (they measure 
only $2 \times 0.5 \mathrm{~mm}$ ). Because direct observations required a limited numbers of behavioural acts among the groups of ten glass eels, no more than five chironomidae were delivered. The low level of feeding could have been zero prey, but agonistic acts were very scarce outside the feeding period, and it would have precluded any possibility of analyzing differences in agonistic behaviour according to feeding level. Feeding was maintained at two low levels, by distributing five or two live chironomidae per set of $12{ }^{\circ} \mathrm{C}$ and $14{ }^{\circ} \mathrm{C}$ aquaria. So, the experimental design consisted in the control of two cross-factors, food and temperature, and four pseudo-replicates per condition.

\section{> BEHAVIOURAL DATA}

Observations and feeding started on the 7th, but due to the lack of description on glass eels aggressive acts in literature and the rare feeding events, data collection started on 20 March. By the 15th, diurnal feeding developed and aggressive behaviour was observed. Between 20 March and 13 April, 16 sampling were conducted. Each sampling consisted in a morning observation of the spatial location and behaviour of glass eels and in an afternoon sampling of feeding and agonistic behaviour. During the morning sampling, each aquarium was observed for 8-9 min and two behavioural variables were considered:

(1) grouping (alone or in contact with another fish);

(2) activity (motionless or swimming).

Aggressiveness was rarely observed during this period and so will only be considered during the afternoon observations realized during feeding. Afternoon sampling started at 14:00 just after feeding and lasted 15 min per aquarium. Three additional behavioural variables were considered:

(3) attack (aggressive act from nose push to bite, given);

(4) reception (aggressive act from nose push to bite, received);

(5) ingestion (quantity of chironomidae actually eaten per individual).

We summed the various items over the 16 days study period for each individual, hence considering the individual as the statistical unit. Dead individuals were replaced to maintain uniform conditions of density, but they were not used in further analysis. Glass eel density was maintained constant because food being a limiting factor, feeding levels would have been difficult to adjust as food items were in limited numbers.

\section{> BIOMETRIC DATA}

In experiments involving behavioural sampling, fish have to be kept alive and so only wet weight can be used to approximate energetic stores losses. Because of the strong relationship between weight and length, condition factor is generally used. It has also been used here even if metamorphosis can potentially interact. Fish were kept in aquaria four days more at $8{ }^{\circ} \mathrm{C}$ without feeding, and on 18 April they were measured, weighed and their pigmentation stages assessed. Biometric data were combined to build a body condition index, BC $=1000 \times$ (weight·length ${ }^{-3}$ ) with weight and length expressed in $\mathrm{mg}$ and $\mathrm{mm}$, respectively.

- Three biometric variables were used. BCi: initial body condition (3-6 March), BCf: final body condition (18 April), and varBC: difference between BCf and BCi.

- Two variables were linked to pigmentation process. Psi: initial pigmentation stage (qualitative variable from 5B 6A0, 6A1, 6A2, 6A3; in order of increasing pigmentation), Psf: final pigmentation stage.

\section{> STATISTICAL ANALYSIS}

The statistical analysis was carried out in two steps. We first analyzed the influence of experimental factors (temperature and feeding) on the variation in body condition, while accounting for the hierarchical nature of the protocol. In a second step, we analyzed 


\section{Table I}

A) Biometric data at the initial (3-6 March) and final (18 April) measurement steps.

B) Distribution of pigmentation stages (in percentage) on 3-6 March (initial measurement) and 18 April (final measurement).

\section{Tableau I}

A) Données biométriques à l'étape initiale (3-6 mars) et finale (18 avril).

B) Distribution (en pourcentage) des stades pigmentaires initiaux (3-6 mars) et finaux (18 avril).

A)

\begin{tabular}{|l|c|c|c|}
\hline & Initial & Final & Variation \\
\hline Mean length & 71.95 & 69.94 & -2.01 \\
\hline SD & 1.58 & 1.73 & 1.01 \\
\hline Mean weight & & & \\
\hline SD & 309.2 & 244.26 & -64.94 \\
\hline & 31.25 & 39.1 & 31.09 \\
\hline Mean body condition & & & \\
\hline SD & 0.83 & 0.71 & -0.12 \\
\hline
\end{tabular}

B)

\begin{tabular}{|l|c|c|}
\hline & Initial & Final \\
\hline 5B & 8.7 & 0 \\
\hline 6A0 & 12.1 & 0 \\
\hline 6A1 & 25.5 & 0 \\
\hline 6A2 & 34.9 & 1.4 \\
\hline 6A3 & 18.1 & 25.5 \\
\hline 6A4 & 0.7 & 46.3 \\
\hline 6B & 0 & 26.8 \\
\hline
\end{tabular}

the relationships between the residuals of the previous analysis, the behavioural variables and the body condition variation.

To analyze the influence of temperature and feeding rate, we used a hierarchical general linear modeling approach, based on a Gaussian error distribution. The model structure was designed as follows:

$$
\operatorname{varBC}_{i, j}=\alpha+\beta \mathrm{T}+\gamma \mathrm{F}+\delta \mathrm{TF}+\eta_{j} \mathrm{~A}+\varepsilon_{i, j}
$$

where $\operatorname{varBC}_{i, j}$ is the condition factor variation of the ith fish in the $j$ th aquarium, $\mathrm{T}$ is the temperature factor, $\mathrm{F}$ the feeding factor, and $\mathrm{A}$ the aquarium fixed effect, nested under the $\mathrm{T}$ and $F$ factors. $\alpha, \beta, \gamma, \delta$ and $\eta_{j}$ are the parameters of the general linear model, and $\varepsilon_{i, j}$ are the residuals. The model was fitted using the GLM package from R software. Significance of each factor was assessed by running an ANOVA on the deviance scores of the model.

To investigate the relationships between variation in morphometry and individual behaviour, a multivariate descriptive analysis, MCA (Multiple Correspondences Analysis), was carried out on residuals of the previous GLM analysis, transformed in qualitative variables. For each variable, four classes were designed; limits of classes were chosen in order to obtain similar 


\section{Table II}

Class limits according to the division of each variable into four modalities of similar numbers. $B C=$ body condition.

Tableau II

Limites de classes résultant du découpage des variables en quatre modalités d'effectifs semblables. $\mathrm{BC}=$ facteur de condition .

\begin{tabular}{|l|c|c|c|c|}
\hline Variables & $1^{\text {st }}$ quartile & $2^{\text {nd }}$ quartile & $3^{\text {rd }}$ quartile & 4th quartile \\
\hline BC variation & {$[-0.369 ; 0.162]$} & ]$-0.162 ; 0.106]$ & ]$-0.106 ; 0.057]$ & ]$-0.057 ; 0.069]$ \\
\hline Initial BC & {$[0.663 ; 0.791]$} & ] $0.791 ; 0.834]$ & ] $0.834 ; 0.865]$ & ] $0.865 ; 1.011]$ \\
\hline Grouping & {$[1 ; 4]$} & ] $4 ; 6]$ & ] $6 ; 8]$ & ] $8 ; 13]$ \\
\hline Activity & {$[0 ; 0]$} & ] $0 ; 1]$ & ] $1 ; 4]$ & ] $4 ; 12]$ \\
\hline Attack & {$[0 ; 1]$} & ] $1 ; 3]$ & ] $3 ; 5]$ & ] $5 ; 25]$ \\
\hline Reception & {$[0 ; 0]$} & ] $0 ; 3]$ & ] $3 ; 6]$ & ] $6 ; 26]$ \\
\hline Ingestion & {$[0 ; 1]$} & ] $1 ; 2]$ & ] $2 ; 5]$ & ] $5 ; 21]$ \\
\hline
\end{tabular}

observation numbers per class (Table I). The MCA design was chosen because several of the behavioural variables had discrete and biased distribution, thus preventing the use of Principal Component Analysis.

Finally, we also checked the correlation between pigmentation stages and variation in body condition. Indeed, the development of pigmentation represents an external parameter of the metamorphosis process. A non-parametric approach was chosen in relation to the low number of fish in some classes ( $5 \mathrm{~B}$ and $6 \mathrm{~A} 0$ ). These two pigmentation stages were grouped (early stages) and compared to another group (late stages) gathering pigmentation stages from $6 \mathrm{~A} 1$ to $6 \mathrm{~A} 4$. These groups were tested for difference in initial and final condition factor as well as in condition factor variation (Wilcoxon tests). In a second step, Wilcoxon tests were conducted to search for a difference between early and late initial stages according to the five behavioural variables.

\section{RESULTS}

Eleven individuals were discarded from the analysis ( 7 deads, 3 individuals with uncertain identity and 1 outlier). The mean size, length and condition factor decreased between 3-6 March and 18 April (Table IA). Meanwhile, 5B, 6A0 and 6A1 pigmentation stages, which initially represented $46 \%$ of the lot, were no more present, and $6 \mathrm{~A} 4$ became the most represented stage $(46 \%$, Table IB).

\section{> EFFECT OF EXPERIMENTAL FACTORS}

We found significant and combined effects of feeding level and temperature. Condition factor loss was higher at low feeding level than at high feeding level $(P=0.002$, Table III). Temperature effect was detected only at low feeding level, with high temperature inducing a higher body condition loss (significant interaction, $P=0.023$, Table III). Overall, only $9.2 \%$ of variation in body condition was explained by our experimental factors (Figure 1). We found considerable variance between pseudo-replicates inside each experimental block $(18.8 \%$, $P=0.001$, Table III). This was especially noticeable for low feeding/high temperature and high feeding/low temperature conditions (see Figure 1). We checked that there was no difference in agonistic behaviour according to feeding level (Wilcoxon test, aggressions, $P=0.11$, receptions, $P=0.24$ ) or in activity according to temperature level (Wilcoxon test, $P=0.97$ ). 


\section{Table III}

ANOVA on deviance scores of the GLM. Statistical significance was assessed using the $F$ statistic. $P$-values are given for $\alpha=0.05 .{ }^{*}$ symbols indicate significant factors. The total deviance was 0.9964 , the residual deviance was 0.7171 .

\section{Tableau III}

Résultats de I'ANOVA conduite sur les scores de déviance du GLM. La signification statistique de l'ANOVA est basée sur la valeur de $F$. Les valeurs de $P$ sont données pour $\alpha=0.05$. Les astérisques désignent les valeurs significatives. La déviance totale est de 0.9964, et la déviance résiduelle de 0.7171.

\begin{tabular}{|l|c|c|c|c|}
\hline Factors & $\begin{array}{c}\text { Degree of } \\
\text { freedom }\end{array}$ & $\begin{array}{c}\text { Deviance } \\
\text { explained }\end{array}$ & F statistic & P-value $(\alpha=0.05)$ \\
\hline Feeding level & 1 & 0.05445 & 10.098 & $0.002^{\star \star}$ \\
\hline Temperature level & 1 & 0.00858 & 1.590 & 0.209 \\
\hline Interaction & 1 & 0.02851 & 5.288 & $0.023^{\star}$ \\
\hline Aquarium effect & 2 & 0.18773 & 2.901 & $0.001^{\star *}$ \\
\hline
\end{tabular}

\section{> EFFECT OF BIOMETRIC AND BEHAVIOURAL VARIABLES}

We retained the two first axes of the MCA according to the Scree test (Catell, 1966; Figure 2). The first axis was mainly correlated to behavioural variables (correlations from 0.23 to 0.57 ) whereas the two body condition variables were poorly represented on this axis (correlations: 0.05 and 0.08 ). This axis mainly opposed two groups of individuals: the first one presenting low feeding and agonistic levels, the second one displaying intermediate to high feeding and agonistic levels. This discrimination on general agonistic behaviour implies that aggressive individuals also suffer aggressions from other, whereas passive individuals generally avoid aggression. On the second axis, body condition variables were best represented $(0.36$ for $\mathrm{BCi}$ and 0.15 for varBC) as well as activity and grouping variables ( 0.39 and 0.47 respectively). The analysis clearly opposed lonely individuals with high initial body condition, high body condition variation, and high activity to gregarious individuals presenting low initial body condition, low body condition variation and low activity.

\section{> INTERACTIONS BETWEEN PIGMENTATION STAGES, BEHAVIOUR AND CONDITION FACTOR}

We found that initial body condition was partly linked to pigmentation: early stages had a higher initial condition factor than late stages $(5 \mathrm{~B}+6 \mathrm{~A} 0$ group versus $6 \mathrm{~A} 1+6 \mathrm{~A} 2+6 \mathrm{~A} 3$ group, Wilcoxon test, $P=0.002$ ). We also found that the early stages group presented a higher body condition loss (Wilcoxon test, $P=0.004$ ). However, these two groups did not differ with respect to final condition factor (Wilcoxon test, $P=0.245$ ). Our data did not evidence for any behavioural differences according to early and late pigmentation stages (Wilcoxon tests, all $P>0.1$ ).

\section{DISCUSSION}

\section{> METHODOLOGICAL ASPECTS}

The sum of the scores got during the 16 days by each individual for each of the behavioural variable was used as statistical unit. This procedure implies to postulate that behaviour did not varied during the two weeks of sampling. This can reasonably be accepted since sampling started only once diurnal feeding behaviour and aggressiveness were observed in all aquaria. In addition, we checked that temporal trend did not occur for aggressiveness (early 


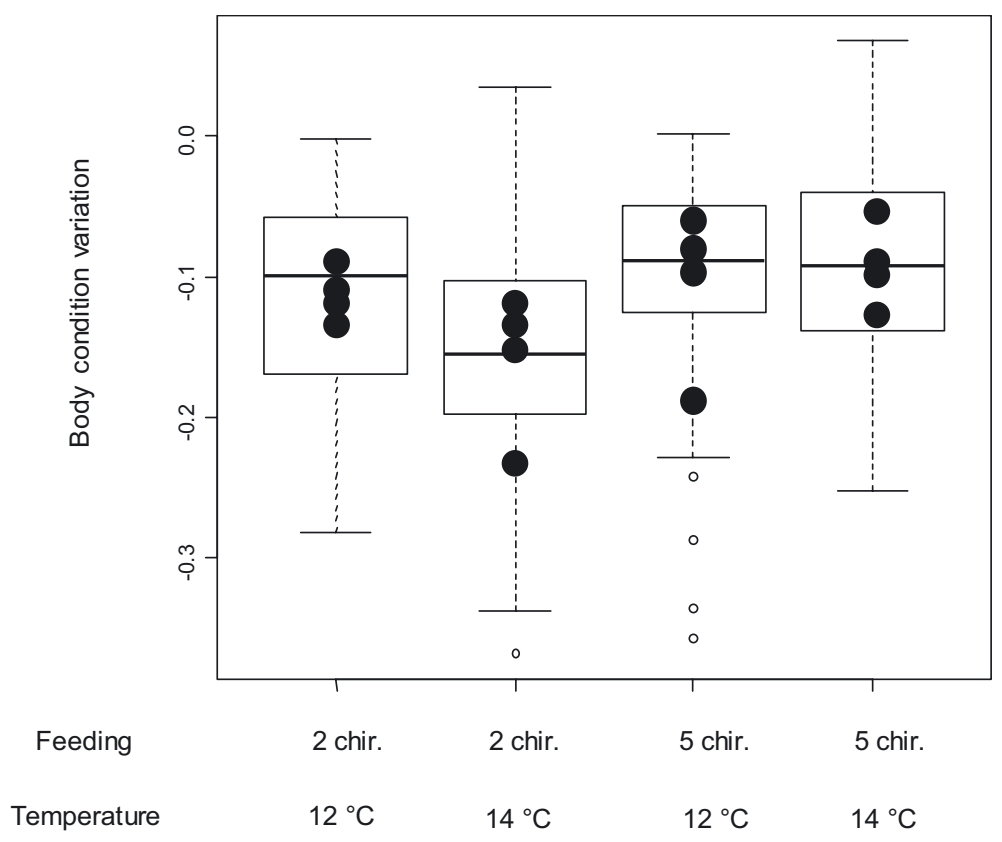

Figure 1

Box plot representing the mean and the quartile distribution of observed body condition variation with respect to experimental conditions (feeding and temperature levels). The solid black dots represent the predictions of the GLM for each experimental condition, accounting for the pseudoreplicative effects (i.e., aquarium effect).

\section{Figure 1}

Boîtes à moustache représentant la moyenne, les $1^{\mathrm{er}}, 2^{\text {ème }}$ et $3^{\mathrm{ème}}$ quartiles, ainsi que les individus en dehors (points blancs) de la distribution pour l'évolution du facteur de condition en fonction des conditions expérimentales (température et alimentation). Les points noirs représentent les prédictions du GLM pour chaque pseudo réplicat (effet aquarium).

models, data not shown). However, this trend was obvious in ingestion behaviour. The experiment started only when almost all chironomidae were consumed in $24 \mathrm{~h}$. However, feeding during the 15 min of observations concerned only $1 / 8$ of preys offered during the first three days and it increased regularly to reach $50 \%$ on day 9 and $75 \%$ at the end of the experiment. So, the "ingestion" behavioural parameter represents fish which exhibited a high motivation toward food, leaving their shelters and fighting to get food as soon as it was distributed. Global feeding (which includes feeding outside the observation period) was unknown and this probably explains the lack of relation between ingestion and body condition variation. Another explanation lies in the fact that MCA was conducted on residuals from the GLM analysis, and therefore, the variance due to the level of feeding has been removed. The temporal trend in "ingestion" behaviour can be considered as an increasing motivation in getting food as soon as it was available, or as a progressive adaptation to diurnal feeding. Indeed, light can be considered as inhibitory on glass eel activity. According to Dou et al. (2003), activity time per hour is repressed at low temperature $\left(15^{\circ} \mathrm{C}\right.$, compared with 20 and $\left.25^{\circ} \mathrm{C}\right)$ and during daylight. At $15{ }^{\circ} \mathrm{C}$, the Japanese pigmenting eel spend $5 \%$ of their time outside the sand at night and $2 \%$ during daylight, and in both periods they remain inactive most of the time (>90\%). In the present experiment, daylight was maintained at a low level (10 lux at the most), whereas it was 400-500 lux in Dou et al.'s experiment (op. cited). On average, $15 \%$ of fish were classified as active. Comparison with Dou et al.'s results (op. cited) is not direct as "activity" was not sampled with the same procedure. However, activity level in the present experiment does not seem to be as negligible as in Dou et al.'s study, maybe in relation with the nature of shelters which were much easier to reach and to leave than sand. 

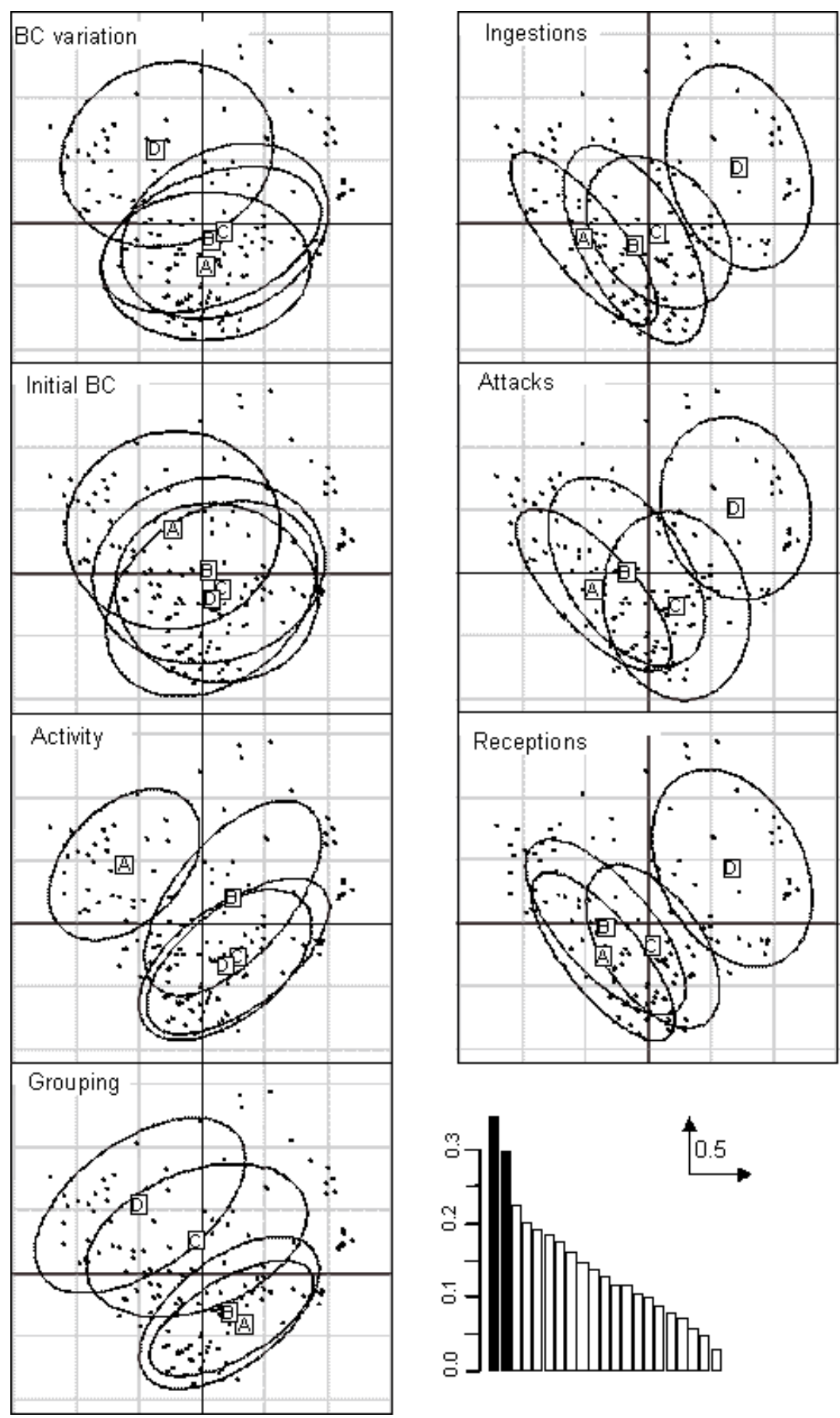

\section{Figure 2}

Factorial plot of the ACM based on the two first axes, for each of the behavioural and biometric variable. For each variable, the barycentre of each modality $(A, B, C$ or $D)$ is plotted starting from the highest to the lowest value. Ellipsoids represent the $90 \%$ presence probability area for a given modality. The distribution of eigenvalues is provided as well as the base coordinates for the factorial plot. BC = body condition.

Figure 2

Plan factoriel de l'ACM sur les deux premiers axes, pour chacune des variables comportementales et biométriques. Pour chaque variable, les barycentres de chacune des quatre modalités sont affichés, de la plus forte à la plus faible valeur (A, B, C et D). Les ellipses représentent $90 \%$ de probabilité de présence dans la modalité. La distribution des valeurs propres ainsi que l'unité de base du plan factoriel sont indiquées. $\mathrm{BC}=$ facteur de condition. 


\section{> RELATIONSHIPS BETWEEN FEEDING, TEMPERATURE AND CONDITION FACTOR}

The numbers of ingestion per fish tended to be higher at high temperature (1.5 and 3.5 prey per fish on average at $12{ }^{\circ} \mathrm{C}$, and 2.9 and 5.6 at $14{ }^{\circ} \mathrm{C}$, respectively at the low and high feeding level). Even if fish were less prompt to feed at the lower temperature, feeding did occur at $12{ }^{\circ} \mathrm{C}$ contrary to Elie's observations (1979). Concerning the threshold of $14{ }^{\circ} \mathrm{C}$ and the upriver movement, level of activity can account for an index of propensity to migrate as it represents swimming fish. However, it was similar at the two temperatures. So, present results do not confirm that a drastic change in feeding or swimming behaviour occurs between $12{ }^{\circ} \mathrm{C}$ and $14{ }^{\circ} \mathrm{C}$.

Feeding levels significantly affected the loss in body condition, whereas the role of temperature was more difficult to analyze. Indeed, it influenced differently condition factor variation depending on the feeding level (Figure 1). In eel, high temperature usually favors growth (e.g. Dou et al., 2003). This was observed at the higher feeding level. However, at the very constraining feeding level (2 chir.), the high temperature is likely to increase metabolic expenditure, and food intake was probably too low to compensate readily for it.

The MCA analysis conducted on the GLM residuals showed that fish with the highest initial body condition were also the most prone to lose in body condition. High losses were also positively associated to high swimming activity and less gregarious fish. Fish grouping and swimming activity are somehow related as fish in swimming activity cannot be classified as gregarious, but inactive fish (which represent the majority of the observations: $84 \%$ of the fish got a score under 6 , whilst $33 \%$ were never observed swimming) can be classified as gregarious or solitary. However, MCA analysis discriminated fish according to high activity and low grouping and so it happens difficult to distinguish the respective importance of these two variables. High swimming behaviour will increase energetic expenditure, whilst the relation with fish loneliness is more difficult to build and so logically, we favor the "high activity" hypothesis. The number of ingested chironomids as well as the agonistic behaviour did not relate to the variation in body condition and they were very dependent: the less aggressive fish were also the less attacked and they got the lowest access to prey. Agonistic behaviour has rarely been described in eels, even if it is a well known phenomenon in aquaculture. Knights (1987) provided the more accurate description of aggressive acts in Anguilla anguilla. Present observations confirm the description made by Knights (op. cited) except that the respective proportions of agonistic acts were quite different. In the present experiment, mouth-to-mouth threat was rarely observed whereas butt, i.e. pushing with the head, mouth closed, was the most frequently observed behaviour. Such difference can be related to the older age of the individuals used $(>1 \mathrm{~g})$, the greater inter-individual difference in size, as well as the much higher density $\left(1\right.$ to $6 \mathrm{~kg} \cdot \mathrm{m}^{-2}$ ) used in Knights' study (op. cited). One interesting point is that the analysis discriminated mainly on the absence on feeding (39 fish) and the absence of involvement in any agonistic behaviour. A part of fish (20) never exhibited aggressive act toward congener. These 20 fish did not feed and did not suffer aggressive act. Knights (op. cited) also noticed that certain individuals showed little or no behavioural activity. However, means calculated for this group of 20 fish and the 129 remaining did not show differences according to activity, early or late initial and final pigmentation stage and biometric variables (initial, final and variation in length, weight and body condition, data not shown). This passive behaviour can clearly not be linked to any of the other studied variables. Feunteun et al. (2003) proposed two behavioural strategies among the migrating elvers: pioneers would "shift upstream whatever the population parameters and environmental conditions"; on the contrary, founders would "migrate inshore and upstream until they find a suitable and free habitat". One could consider that the few fish which do not try to get any access to food (passive fish) were pioneers waiting for a water current cue. Fasting resistance of glass eels is very high and they can certainly withstand several months of fast at the experimental temperatures used here. For instance, glass eels have been shown to stand 65 days of fasting at $26{ }^{\circ} \mathrm{C}$ (Rodriguez et al., 2005). It is possible that the passive fish of the present experiment remained passive because they were only motivated by 
upstream migration. However, a little flow comes in the aquarium due to the re-circulating water. Fish swimming in the water column were usually localized near this water in-put. Yet, the average level of activity of passive fish was quite similar to the average level of other fishes (2.26 and 2.69 respectively, whereas activity score may vary from 0 to 12 ). So they can hardly be interpreted as founders.

\section{> DEVELOPMENT OF PIGMENTATION AND BIOMETRIC VARIATIONS}

The analysis of pigmentation stage showed that initial condition factor was higher in $5 \mathrm{~B}$ and $6 \mathrm{~A} 0$ fish than in older stages. However, at the end of the experiment, condition factor did not differ among the pigmentation stages: losses were higher among young stages. Analysis did not evidence for differences in behaviour among the two groups of early and late pigmentation stage fish. Thus, it is difficult to discriminate between the respective role of initial pigmentation stage and/or initial condition factor in the observed condition factor variation.

Biometric characteristics of glass eels change according to time. In the wild, two phenomena interact: (i) according to their date of arrivals, glass eels are usually smaller and lighter during the second half of the arrival period (after January) than during autumn and early winter; (ii) as pigmentation progresses, fish lose weight and length diminish as a natural phenomena related to metamorphosis process. This last phenomenon has been studied under experimental conditions, but most often experiments are realized at temperature corresponding to aquaculture practices $\left(>20^{\circ} \mathrm{C}\right)$, and none of them have been conducted the individual level. A noticeable exception concerns Lecomte-Finiger (1983) results obtained at $12{ }^{\circ} \mathrm{C}$. A two months rearing at this temperature led to a reduction in length and weight of $4.2 \%$ and $32.3 \%$, respectively, whereas the body condition remained unchanged until $6 \mathrm{~A} 3$ stage. Our present results led to smaller variations: in 6 weeks, $2.8 \%$ and $21 \%$, respectively in length and weight, whereas body condition reduction reached $14.2 \%$ (all temperature and feeding conditions mixed). Some of the discrepancy between the two studies lies probably in the characteristics of glass eels at the start of the experiment. Indeed, in Lecomte-Finiger's experiment glass eels were caught in December and transparent glass eels (5B, Strubberg, 1913) represented 100\% of the lot, whereas in the present study $5 B+6 A 0$ (Elie et al., 1982) accounted for only $22 \%$ of the initial lot. Yet, loss of weight was higher in young stages $5 B+6 A 0(25 \%)$ than in older stages $6 A 1+6 A 2+6 A 3(20 \%)$. Another part of the difference can be explained by the Mediterranean origin of glass eels in Lecomte-Finiger's study, which are known to be smaller than Oceanic ones (present study). However, initial body conditions were very close: 0.85 in Lecomte-Finiger against 0.83 (SD: 0.06 ) in the present study. Variations were certainly more accurately measured in the present study as biometric data were taken at the individual level. In addition, it was possible to identify dead individuals and remove them from the analysis, which is not possible when sequential measuring concerns batches. Our results can also be compared to data obtained in Adour estuary by monthly sampling at a location close to the tidal limit. Charlon and Blanc (1982) observed between early March and late April a reduction in size and weight of $4 \%$ and $11 \%$, respectively. Meantime, body condition varies little (4\% at the most). By comparing their results to marine sampling carried out at the same dates, Charlon and Blanc (op. cited) concluded that observed changes in biometry were only due to differences in biometrical characteristics of the successive populations arriving all along the year on the coast. One possible explanation to such differences between experimental and field results lies in the possible adoption of a sedentary lifestyle of the thinnest individuals in the course of their estuarine migration (downstream the sampling area) as suggested by Bureau du Colombier et al. (2007). Their presumed absence in the upper estuary sampling could have masked the part of the reduction in size and weight due to metamorphosis process.

\section{CONCLUSION}

In the present experiment feeding level was the limiting factor, supposed to influence competition. However, level of aggressiveness did not vary significantly according to 
feeding level. It can be due to the limited sample size and/or to high variance among results. Also, the number of preys increases aggressiveness as in both cases (high and low feeding levels) fish were fighting for this resource. So, despite the lack of noticeable effect of feeding levels on competition, it remains difficult to conclude. However, because agonistic behaviour was not related to body condition or activity, the density-dependent dispersal hypothesis was not strengthened by present results. Our analysis discriminated a group of fish characterized by high body condition loss, high activity and high initial body condition/early pigmentation stage. Based on present result and in accordance with Imbert et al. (2008), these fish would be the most prone to colonize rivers. Passive fish was the other category of fish discriminated by our work, but their behaviour was not related to body condition or to activity. The characterization of migrant and sedentary eel is in its early stages. Many work remains to better understand which factors are implicated and to give some ground to proposed hypotheses (Ibbotson et al., 2002; Feunteun et al., 2003; Edeline, 2007).

\section{ACKNOWLEDGEMENTS}

We wish to thank M. Jarry and E. Prevost for their precious advice in the choice of statistical methods. E. Huchet provided an invaluable help in the settling of the aquaria and temperature control system.

\section{REFERENCES}

Bardonnet A., Rigaud C. and Labonne J., 2005. Étude expérimentale des comportements de civelles d'Anguilla anguilla L. Influence de la densité et de la disponibilité en abris. Bull. Fr. Pêche Pisc., 378-379, 47-65.

Briand C., Fatin D., Ciccotti E. and Lambert P., 2005. A stage-structure model to predict the effect of temperature and salinity on glass eel Anguilla anguilla pigmentation development. J. Fish Biol., 67, 993-1009.

Bureau du Colombier S., Bolliet V., Lambert P. and Bardonnet A., 2007. Energy and migratory behavior in glass eels (Anguilla anguilla). Physiol. Behav., 92, 684-690.

Cattell R.B., 1966. The scree test for the number of factors. Mult. Behav. Res., 1, 245-276.

Charlon N. and Blanc J.-M., 1982. Étude des civelles d'Anguilla anguilla L. dans la région du Bassin de l'Adour. 1. Caractéristiques biométriques de longueur et de poids en fonction de la pigmentation. Arch. Hydrobiol., 93, 238-255.

Crean S.R., Dick J.T.A., Evans D.W., Rosell R.S. and Elwood R.W., 2005. Survival of juvenile European eels (Anguilla anguilla) transferred among salinities, and developmental shifts in their salinity preference. J. Zool., 266, 11-14.

Daverat F., Elie P. and Lahaye M., 2004. Première caractérisation des histoires de vie des anguilles (Anguilla anguilla) occupant la zone aval du basin versant Gironde-Garonne-Dordogne : apport d'une méthode de microchimie. Cybium, 28, 83-90.

Daverat F., Limburg K.E., Thibault I., Shiao J.-C., Dodson J.J., Caron F.O., Tzeng W.N., lizuka Y. and Wickstrom, 2006. Phenotypic plasticity of habitat use by three temperate eel species, Anguilla anguilla, $A$. Japonica and $A$. rostrata. MEPS, 308, 231-241.

Deelder C.L., 1958. On the behaviour of elvers (Anguilla vulgaris Turt.) migrating from the sea into fresh water. J. Cons. Int. Explor. Mer, 24, 135-146.

Dou S., Miller M.J. and Tsukamoto K., 2003. Growth, pigmentation and activity of juvenile Japanese eels in relation to temperature and fish size. J. Fish Biol., 63, 152-165.

Edeline E., 2007. Adaptative phenotypic plasticity of eel diadromy. MEPS, 341, 229-232.

Edeline E., Lambert P., Rigaud C. and Elie P., 2006. Effects of body condition and water temperature on Anguilla anguilla glass eel migratory behavior. J. Exp. Biol. Ecol., 331, 217-225.

Edeline E., Beaulaton L., Le Barh R. and Elie P., 2007. Dispersal in metamorphosing juvenile eel Anguilla anguilla. MEPS, 344, 213-218.

Elie P., 1979. Contribution à l'étude des montées d'Anguilla anguilla Linné (Poisson, Téléostéen, Anguilliforme), dans l'estuaire de la Loire : Pêche, Écologie, Écophysiologie et Élevage, Thèse de Doctorat de 3ème cycle, Univ. Rennes, France, 372 p. 
Elie P., Lecomte-Finiger R., Cantrelle I. and Charlon N., 1982. Définition des limites des différents stades pigmentaires durant la phase civelle d'Anguilla anguilla (Poisson Téléostéen anguilliforme). Vie Milieu, 32, 149-157.

Feunteun E., Laffaille P., Robinet T., Briand C., Baisez A., Olivier J.M. and Acou A., 2003. A review of upstream migration and movements in Inland waters by anguillid eels: toward a general theory. In: Aida K., Tsukamoto K. and Yamauchi K. (eds.), Eel biology, Springer, 191-213.

Gascuel D., Feunteun E. and Fontenelle G., 1995. Seasonal dynamics of estuarine migration in glass eels (Anguilla anguilla). Aquat. Liv. Res., 8, 123-133.

Hickman R.A., 1981. Densities and swimbladder development of juvenile American eels, Anguilla rostrata (Lesueur) as related to energetics of migration. J. Fish Biol., 18, 507-517.

Ibbotson A., Smith J., Scarlett P. and Aprahamian M., 2002. Colonisation of freshwater habitats by the European eel Anguilla anguilla. Fresh. Biol., 47, 1696-1706.

Imbert H., Arrowsmith R., Dufour S. and Elie P., 2008. Relationships between locomotor behavior, morphometric characters and thyroid hormone levels give evidence of stage-dependent mechanisms in European eel upstream migration. Horm. Behav., 53, 69-81.

Jellyman D.J., 1977. Summer upstream migration of juvenile freshwater eels in New Zealand. N. Z. J. Mar. Fresh. Res., 11, 61-71.

Lecomte-Finiger R., 1983. Anatomical and energetical development of Mediterranean elver (Anguilla anguilla L., 1758) during pigmentation [Translated title]. Vie Milieu, 33, 87-92.

Knights B., 1987. Agonistic behaviour and growth in the European eel, Anguilla anguilla L., in relation to warm-water aquaculture. J. Fish Biol., 31, 265-276.

Moriarty C., 1986. Riverine migration of young eels Anguilla anguilla (L.). Fish. Res., 4, 43-58.

Moriarty C. and Dekker W., 1997. Management of the European eel. Second report of the EC concerted action AIR A94-1939. Fisheries Bulletin (Dublin), 15.

Naismith I.A. and Knights B., 1988. Migrations of elvers and juvenile European eels, Anguilla anguilla L., in the river Thames. J. Fish Biol., 33, 161-175.

Rodriguez A., Gisbert E. and Castello-Orvay F., 2005. Nutritional condition of Anguilla anguilla starved at various salinities during the elver phase. J. Fish Biol., 67, 521-534.

Sasai S., Katoh F., Kaneko T. and Tsukamoto K., 2007. Ontogenic change in gill chloride cells in leptocephalus and glass eel stages of the Japanese eel, Anguilla japonica. Mar. Biol., 150, 487-496.

Sorensen P.W. and Bianchini M.L., 1986. Environmental correlates of the freshwater migration of elvers of the American eel in the Rhode Island brook. Trans. Am. Fish. Soc., 115, 258-268.

Strubberg A., 1913, The metamorphosis of elvers as influenced by outward conditions. Serv. Fisk., 4, $1-11$.

Vollestad L.A. and Jonsson B., 1988. A 13-year study of the population dynamics and growth of the European eel Anguilla anguilla in a Norwegian river: evidence for density dependent mortality and development of a model for predicting yield. J. Anim. Ecol., 57, 983-997.

Wattendorf R.J., 1979. Cannibalism in elvers. Prog. Fish-Cult., 41, 218.

White E.M. and Knights B., 1997. Environmental factors affecting migration of the European eel in the rivers Severn and Avon, England. J. Fish Biol., 50, 1104-1116.

Yamano K., Nomura K. and Tanaka H., 2007. Development of Thyroid gland and changes in thyroid hormone levels in leptocephali of Japanese eel (Anguilla japonica). Aquaculture, 270, 499-504. 